\title{
O DANO EXISTENCIAL NA SOCIEDADE DE CONSUMO
}

\author{
Dennis Verbicaro \\ Doutor em Direito do Consumidor pela Universidade de \\ Salamanca (Espanha), Mestre em Direito do Consumidor \\ pela Universidade Federal do Pará. Professor da \\ Graduação e do Programa de Pós-Graduação Stricto Sensu \\ da Universidade Federal do Pará-UFPA, Professor da \\ Graduação e Especialização do Centro Universitário do \\ Pará, Professor Visitante da Pós-Graduação Lato Sensu \\ em Direito do Consumidor da Universidade Federal do \\ Rio Grande do Sul-UFRGS. É Procurador do Estado do \\ Pará e Advogado. \\ dennis@gavl.com.br

\section{Raíza Cruz} \\ Bacharela em Educação Física, Aluna da graduação em \\ Direito da UFPA e integrante do Grupo de Pesquisa \\ "Consumo e cidadania" (CNPQ/UFPA). \\ raizacscruz@gmail.com
}

RESUMO: O presente artigo, pelo método dedutivo e por meio de pesquisa bibliográfica nacional e estrangeira, tem como objetivo analisar o fenômeno do dano existencial nas relações de consumo. Na sociedade atual, há forte assédio da Indústria Cultural para que o consumidor se submeta a um padrão de consumo voltado para a autossatisfação pessoal, ou mesmo aceitação no meio social. $\mathrm{O}$ apelo midiático em torno da aquisição de bens e serviços atinge sobremaneira a psique dos consumidores, em especial os grupos mais vulneráveis, gerando uma liberdade artificial de escolha e uma felicidade artificial, na medida em que sua insatisfação pessoal com a vida, ou mesmo suas carências emocionais e sociais poderiam ser aplacadas pela satisfação e prazer de comprar. A pesquisa, também, enfrenta a novel discussão acerca da vulnerabilidade comportamental do consumidor diante do assédio de consumo no contexto da hipermodernidade.

PALAVRAS-CHAVE: Dano existencial. Sociedade de Consumo. Indústria cultural. Direito do Consumidor.

\section{The existential damage in the consumer society}

ABSTRACT: The present article, through the deductive method and through national and foreign bibliographic research, aims to analyze the phenomenon of existential damage in consumer relations. In today's society, there is a strong harassment of the Cultural Industry for the consumer to submit to a consumption pattern aimed at personal self-satisfaction, or even acceptance in the social environment. The media's appeal for the acquisition of goods and services overwhelms the psyche of consumers, especially the most vulnerable groups, generating an artificial freedom of choice and artificial happiness, insofar as their personal dissatisfaction with life, or even their Emotional and social needs could be appeased by the satisfaction and pleasure of buying. The research also addresses the novel discussion of consumer behavioral vulnerability to consumer harassment in the context of hypermodernity.

KEYWORDS: Existential damage. Consumer society. Cultural industry. Consumer Law. 


\section{INTRODUÇÃo}

O objeto de estudo do presente ensaio é uma breve análise dos fenômenos que permeiam a perspectiva do dano existencial sofrido pelos consumidores na sociedade atual. A tutela ao consumidor é uma resposta do Direito ao mundo capitalista e às transformações sociais ocorridas ao longo da história, sobretudo com a maior concentração da população na área urbana, o desenvolvimento tecnológico dos bens de produção, o aumento do poder aquisitivo da população, a propagação das técnicas comerciais coercitivas, tudo, levando ao consumo desenfreado de produtos e serviços.

O apelo midiático em torno da aquisição de bens e serviços, através de campanhas publicitárias com forte influência psicológica acabam por forjar novas e transitórias necessidades de consumo a partir de modelos artificiais de felicidade e qualidade de vida, o que leva a uma verdadeira compulsão pelo consumo, seja para satisfazer um sentimento hedonista de autossatisfação, seja para favorecer uma sensação de pertencimento social, em detrimento das necessidades fisiológicas autênticas, ou seja, aquelas relativas à própria subsistência do indivíduo (alimentação, vestuário e etc.).

Assim é que o conceito de bem-estar, para aqueles atingidos pela compulsão do consumo, deixa de ser algo transcendental e passa a ser um bem igualmente consumível. Para esses consumidores, o ato de consumir se transforma em sinônimo de felicidade, de modo que quanto mais prazer no ato de consumo o ser humano é capaz de obter, mais "feliz" ele é. A parte se confunde com o todo, e o prazer, que antes era concebido apenas como um dos fatores propícios à felicidade, é elevado à categoria de verdadeiro arquétipo da felicidade.

O consumo exacerbado nunca fez tanto sentido como na sociedade hipermoderna, porquanto nela encontra o alicerce necessário para se intensificar cada vez mais, alimentado pela permanente insatisfação de seus membros, insatisfação pela certeza de nunca conseguir acompanhar todas a inovação e volatilidade inerente aos símbolos de consumo. Esse comportamento é decorrência lógica dos padrões impostos a todo momento pela indústria cultural de massa, definida como o desenvolvimento de mecanismos de controle das consciências individuais e coletivas, exercido pela imprensa, internet, televisão, rádio e cinema com a finalidade de homogeneizar, adaptar e integrar as massas aos valores capitalistas de consumo.

Importante registrar, também, que a aludida volatilidade dos símbolos de consumo tem na obsolescência programada uma importante ferramenta de convencimento, pois através dela o fornecedor, sob o falso pretexto de garantir a evolução estética ou tecnológica dos bens de consumo, reduz, propositalmente, a projeção de durabilidade dos mesmos, interferindo na expectativa inicial de fruição do consumidor, bem como em sua liberdade de escolha, pois diante das dificuldades técnicas de manter o funcionamento do produto, ou mesmo de fazer uso de novas qualidades incompatíveis com o modelo atual, o consumidor será levado a adquirir o mais novo lançamento do mercado.

A busca frenética pelos bens de consumo é a busca, na verdade, por uma pseudoliberdade, que mascara uma real infelicidade do indivíduo e seu crescente mal-estar pessoal e social, daí porque o reconhecimento desse diagnóstico social nos leva ao reconhecimento de uma nova categoria de dano: o dano existencial nas relações de consumo.

Diante desse contexto, o presente artigo, através do método dedutivo e de pesquisa bibliográfica nacional e estrangeira, tem por objetivo fazer um diagnóstico sócio-filosófico do consumo na atualidade, para, num segundo momento, demonstrar que a perda de legitimidade do Estado de mal-estar social e o agravamento da vulnerabilidade comportamental do consumidor, aqui compreendido como categoria, estão diretamente relacionados com o crescimento 
exponencial das práticas abusivas e fortalecimento da posição jurídica e econômica do fornecedor, dando ensejo ao surgimento de um dano difuso e compartilhado por todos: o dano existencial pela certeza de não se alcançar o idealizado e fantasiado padrão de qualidade de vida proposto pela indústria cultural a serviço do capitalismo predatório.

\section{SOLIDARIEDADE E CIDADANIA - A IMPORTÂNCIA DA PARTICIPAÇÃO CÍVICA NA TUTELA AO CONSUMIDOR.}

A Constituição de 1988 surge como um marco de consagração do capitalismo e da economia de mercado no Brasil, além de ensejar o surgimento da disciplina e reconhecimento dos direitos dos consumidores, pela primeira vez no constitucionalismo brasileiro, considerado enquanto direito fundamental.A disciplina Direito do Consumidor emerge como um necessário instrumento de manutenção do sistema econômico. (OLIVEIRA, 2017)

A tutela ao consumidor implica inexoravelmente em uma relativa restrição ao exercício da atividade econômica. Um dos princípios utilizados na proteção consumerista é o princípio da harmonia das relações de consumo, com previsão no caput do artigo 170 (trata da livre iniciativa) e do inciso V (tutela ao consumidor), ambos dispositivos presentes na Constituição da República. O Estado, dessa forma, funciona como um mediador de suma importância no processo.

O Estado brasileiro, no âmbito da proteção do consumidor, ao mesmo tempo em que reconhece o exercício da atividade econômica e da livre iniciativa, estabelece padrões éticos de comportamento que irão tornar aquela liberdade relativa, não caracterizando um Estado intervencionista, mas representa uma ruptura com o modelo liberal, que visaintervir no sentido de equalizar as relações consumeristas.

Historicamente, os indivíduos que compunham a sociedade tinham a noção e liberdade atrelada à participação na esfera política da nação, no entanto sem priorizar seus interesses em detrimento das preocupações coletivas da sociedade, já que a liberdade exercida era a positiva. (VERBICARO e VERBICARO, 2016) A liberdade negativa é a liberdade do indivíduo para escolher como administrar sua vida sem coação dos outros, ocupando-se basicamente consigo e com os seus.

Depreende-se da liberdade negativa propagada na história moderna, um convite ao egoísmo e à resignação política. Não obstante, sob a égide do Estado e do Direito, o individualismo e a concepção e liberdade negativa atendia de maneira velada aos interesses burgueses, radicado pelas promessas da modernidade, que encontraram suporte num idealismo vazio da sociedade, elaboradas pelo capitalismo liberal, sob a suposta legitimidade da razão, da ciência e do Direito. (VERBICARO e VERBICARO, 2016)

A idéia de participação política e solidariedade entre os consumidores está ligada também a uma concepção de justiça social. A Política Nacional das Relações de Consumo encontra suporte no conceito de liberdade positiva, pautada na solidariedade e corroborada pela idéia de que a liberdade constitui uma das maiores expressões da justiça. Como conseqüência dos padrões de comportamento impostos pela indústria cultural, a sociedade de consumo não consegue visualizar a importância a solidariedade como instrumento libertador.

A ruptura com o individualismo das democraciasliberais, marcadas pelos sentimentos de egoísmo, competitividade e indiferença, visando o não comprometimentoda liberdade negativa, visa ao fortalecimento de virtudes do instinto de sociabilidade, único capaz de confrontar para corrigir as mazelas da democracia, a exemplo da falta de compromisso e credibilidade na 
representação política, concepções utilitaristase a própria acomodaçãoda cidadania, que faz dessa passividade um importante mecanismo de alienação. (OLIVEIRA, 2017)

A questão que permeia essa idéia de solidariedade é uma atuação política plural e consertada, ou seja, é a proposição de uma educação cívica eficiente e bem organizada. Educação essa que seja capaz de gerar modificação na forma de enfrentamento de diversas situações presentes no cotidiano, as quais causam uma felicidade momentânea e conduzem o indivíduo a agir com indiferença em relação ao outro e inerte mediante as ações políticas.

Uma participação política efetiva é fundamental para o próprio sentido de vida, pois não há frustração maior do que desperdiçar a experiência e, ao final da vida, constata-se que, na verdade, deixou-se de viver. É importante resgatar o sentido do prazer solidário, único capaz de modificar estruturas viciadas de poder e opressão. Isso quer dizer que quando se tem medo de exercer a liberdade positiva, a pretexto de proteger a liberdade negativa (comodidade individual dos prazeres materiais), renuncia-se a viver plenamente e passa-se para um estado de morte moral.

O capitalismo preleciona que a competitividade e o individualismo constituem os melhores caminhos para o sucesso. Como consequência, o homem desenvolve uma obsessão para ostentar o poder e o prestígio social, em detrimento dos interesses dos mais débeis e frágeis, que passarão a lhe servir não como algo digno de reprovação moral, mas natural e inerente ao jogo social em que uns, necessariamente, serão mais bem sucedidos que outros e estes, por sua vez, deverão se resignar ao seu estado de servidão e subserviência.

Los placeres de éxito personal, el llegar a ser alguien en la vida, el contar con el reconocimento público, o, en otro orden de cosas, despertar admiración por la rara habilidad de destacar en las cosas más variadas, desde ser una buena cantante de ópera, una excepcional sex- symbol o un coleccionista de obras de arte, habilidad para marcar goles o estafar al fisico, etc., son algunas de las metas. Vivimos en una sociedad realmente curiosa en la que los seres humanos parecen buscar compulsivamente el éxito y el aplauso social.(GUISÁN, 2000, p.67)

O triunfo pessoal na vida se torna a única batalha pública do indivíduo, já que as demais cederam espaço à moral socrática de auto-respeito e êxito de si mesmo. A participação na vida pública se resume a uma meta pífia de satisfação pessoal.

\footnotetext{
Kant, como muchos, piensa equivocadamente que la felicidad personal sólo se consigue en la persecución de los fines próprios, cuando desde Platón a Mill ha sido demonstrado fehacientemente que la mejor, más profunda, más honda felicidad privada es la que se deriva de nuestra cooperación generosa en los asuntos públicos. Por lo demás, tener que decirse uno a sí mismo "soy un indigno" es una de las formas más claras de decirse uno a sí mismo que ha fracasado en el nivel más profundo de su personalidad y es, por consiguiente, su conducta causa no tan sólo de horror moral, sino de infelicidad desgarradora. (GUISÁN, 2000, p.68)
}

De acordo com essa perspectiva, de que a moral está diretamente atrelada à verdadeira felicidade, pode-se concluir que todo aquele que vive convulsionado pelo gigantismo de seu individualismo, aprisionado, ou corrompido de alguma maneira, não é apenas um parasita social que causa dano ao seu entorno, mas, sobretudo, é um ser humano moralmente enfermo com incapacidade para desfrutar dos prazeres verdadeiros e profundos. Leia-se aí a realização pessoal de servir ao próximo e vivenciar o crescimento e harmonia do grupo social.

O autorrespeito, o amar-se, o sentir-se autossatisfeito são alguns dos modos mais apropriados para recuperar a saúde moral e transformar o homem em uma pessoa que goza e produz o gozo na convivência social. 
Nesse sentido, a educação cívica desperta o sentimento de empatia social entre os consumidores, culminando com uma nova geração de consumidores, que pensa coletivamente e sabe agir politicamente. A educação para um consumo solidário é uma das principais metas da Política Nacional das Relações de Consumo no Brasil e busca formar cidadãos combativos e atentos às práticas abusivas e conscientes do seu poder de escolha no mercado. (VERBICARO, 2017)

\section{A INDÚSTRIA CULTURAL E SUA MALÉFICA INFLUÊNCIA NAS RELAÇÕES DE CONSUMO}

A expressão indústria cultural foi cunhada inicialmente pelos filósofos e sociólogos alemães Theodor Adorno e Max Horkheimer na obra Dialética do Esclarecimento, publicada ela primeira vez em 1944. Rejeitando o termo cultura de massa, Indústria Cultural designa a produção de cultura a partir dos moldes da indústria, cultura essa voltada ao consumismo, oferecendo produtos que promovem uma satisfação transitória e efêmera.

Essa oposição conceitual deveu-se ao fato de que a concepção de cultura de massa remonta a uma cultura produzida pela própria massa populacional, contemporaneamente chamada de arte popular. Na indústria cultural, o fenômeno é divergente. A indústria cultural consiste em manifestações produzidas sob a égide do capital.

A Indústria cultural encontra escopo atualmente no desenvolvimento de mecanismos de controle das consciências individuais e coletivas exercidos pelos meios de comunicação em massa, tais como rádios, televisão, cinema, jornais, revistas, redes sociais, sem o cuidado de reproduzir fidedignamente a cultura espontânea produzida e ressignificada na sociedade, mas visando padronizar e adaptar as massas aos valores capitalistas de consumo.

Todo esse aparato culmina por criar de forma explícita ou subliminar necessidades de consumo crescentes, através de um aprimorado processo de racionalização dos meios de produção, padronização, difusão e divulgação de bens de consumo como produtos culturais. A cada dia são criadas novas necessidades, que atendem e agradam aos indivíduos, submetendoos a seu monopólio e tornando-os acríticos.

Essa aceitação por parte dos consumidores, com pouca ou nenhuma resistência, decorre de uma análise da indústria cultural prévia ao lançamento da mercadoria, sugerindo novas necessidades. Dessa maneira, a autonomia da vontade é substituída por um jogo com final premeditado entre quem conhece as regras e quem as desconhece. "A verdade em tudo isso é que o poder da indústria cultural provém de sua identificação com a necessidade produzida" (ADORNO e HORKHEIMER, 1985).

Tem-se aí uma permanente necessidade de autoafirmação do consumidor, que busca imitar comportamentos e hábitos de consumo de uma realidade criada pela malsinada indústria cultural, que, subliminarmente, funcionaliza as escolhas do consumidor de acordo com o padrão global de consumo do qual ele não participa como fonte indicativa de suas necessidades, mas apenas como integrante da massa subserviente de financiamento desse círculo vicioso de um consumismo inconsciente e irresponsável.

Inicialmente, a premissa de atuação capitalista era pautada na satisfação de necessidades existentes, com as ofertas produzidas em resposta à demanda corrente. Entretanto, com o passar dos anos, uma modificação de fundamental importância na estrutura social ensejou modificações na sistemática comercial. A sociedade evoluiu de produtores a uma sociedade de con- 
sumidores, sendo os lucros oriundos sobretudo da exploração dos desejos de consumo. (BAUMAN, 2010)

Atualmente, a finalidade do negócio é evitar que as necessidades sejam satisfeitas e induzir a novas necessidades que clamam por satisfação e novos clientes em potencial. Em relação à filosofia dos negócios, os empréstimos não são exceção: a oferta de empréstimos deve criar e ampliar a necessidade de empréstimos. Outra reviravolta no sistema capitalista foi a introdução dos cartões de crédito, há cerca de 30 anos. O slogan usado foi "Não adie a realização do seu desejo". (BAUMAN, 2010)

De posse do cartão de crédito, o consumidor tem a possibilidade de administrar seus desejos e anseios. Efetivamente, essa é uma oferta que muito seduz. Um mecanismo de satisfação imediata, sem a necessidade de economizar para depois fruir esse sacrifício, a ordem natural. Para impedir que o efeito dos cartões de crédito e do crédito fácil se reduza a um lucro que o emprestador só realiza uma vez com cada cliente, a dívida contraída tinha de ser transformada numa fonte permanente de lucro.

Para os bancos credores, não seria vantajoso que seus devedores pagassem suas dívidas, ao menos não nos prazos previstos. Se eles pagassem com diligência os seus débitos, não seriam mais devedores. E os débitos resultantes de juros configuraram-se na maior fonte de lucros constantes do sistema bancário. (BAUMAN, 2010)

$\mathrm{O}$ crescimento da sociedade atual atrelado à sua complexidade culmina com novas espécies de danos à pessoa. O Direito, acompanhando as transformações sociais, necessita de constante atualização e diálogo com essas peculiaridades que vão surgindo com a evolução da sociedade. Nesse sentido, a Responsabilidade Civil se configura como o principal instituto de tutela às violações de Direitos Humanos. (MELLO, 2014)

No mundo atual, que prega tanto o imediatismo, a superficialidade presente nas relações, nos encontros, nas diversões, nas músicas que se ouve, nos livros que se lê, notadamente banais, tampouco evocando o que há de mais nobre, aquilo que faz pensar, tudo preparado pela indústria cultural para os consumidores, sob a égide do comodismo,torna cada vez mais difícil o rompimento e questionamento acerca da realidade em que se vive.

\section{O DANO EXISTENCIAL NA PERSPECTIVA DA RESPONSABILIDADE CIVIL CONSUMERISTA}

A função garantidora da Responsabilidade Civil tutela principalmente os chamados danos não patrimoniais. Pautado na idéia da dignidade da pessoa humana, a dupla função da responsabilidade civil não patrimonial está relacionada com a tutela dos interesses do homem, ao mesmo tempo em que possui um caráter eminentemente preventivo, no sentido de evitar novos danos a esses bens jurídicos. (OLIVEIRA, 2017)

A responsabilidade civil parte do pressuposto de que as violações, as quais ocorrem através de um ato lícito ou ilícito, geram o dever de reparação, considerando o dever jurídico originário de não causar danos a outrem, sob pena de gerar um dever jurídico sucessivo, o de reparação ao dano causado.

O dano pode ser entendido, grosso modo, como uma lesão a um bem jurídico tutelado que potencialmente gere prejuízo na esfera patrimonial ou extrapatrimonial. A responsabilidade civil deve estar atrelada ao dano, sua condição de existência. A concepção de dano é facilmente relacionada a algo quantificável, noção que se aplica aos danos patrimoniais. Os danos 
não patrimoniais ou morais, por sua vez, são aqueles que atingem interesses insuscetíveis de avaliação pecuniária. (CHAMONE, 2008)

A responsabilidade civil vem assumindo novos contornos, em grande parte devido aos avanços sociais, fato que gera modificação dos conflitos, que evoluem deixando de atingir somente a esfera do indivíduo para alcançar a coletividade. Assim, a discussão em torno da responsabilidade civil mediante os novos conflitos alcança maiores projeções, especialmente no que diz respeito ao dano moral coletivo, pois este instituto tutela uma nova modalidade de direitos, a dos direitos ou interesses sociais. (MELLO, 2014)

Por interesses difusos, entendem-se aqueles relacionados a grupos sem vínculo jurídico, ou grupos menos determinados de indivíduos. Referem-se não ao indivíduo especificamente, mas ao sujeito enquanto membro da sociedade. Os interesses coletivos, também chamados de Direitos de terceira dimensão, são resultados das lutas travadas por movimentos sociais, na transição da década de 50 a 60. (MELLO, 2014)

Outra característica dos interesses coletivos é que são transindividuais, ou seja, superam a esfera do indivíduo, e são caracterizados por possuírem objeto indivisível, e por atingirem um número determinável de pessoas, ligadas entre si ou com a parte contrária por uma relação jurídica base. No que tange aos interesses individuais homogêneos, consistem em interesses de grupos com sujeitos determináveis que possuem pretensões comuns. Representa um único fato gerador de diversas pretensões indenizatórias. (MELLO, 2014)

No Código civil, o legislador mantém a distinção entre o caráter punitivo da sanção penal e o caráter reparatório da sanção civil. Dessa forma, a indenização sem dano importaria em enriquecimento ilícito para quem a recebesse e pena para quem a pagasse. Ressalta que o objetivo da indenização é reparar o prejuízo experimentado pela vítima, visando reintegrá-la ao estado em que se encontrava antes da prática do ato ilícito. (CHAMONE, 2008)

A dupla função da responsabilidade civil nos danos não patrimoniais (compensar e punir) está intrinsecamente relacionada à noção de centralidade da pessoa, já que, no caso concreto, há a necessidade de se fixar e quantificar uma indenização que não só satisfaça as pretensões do lesado, mas que previna a ocorrência de novos danos a esse bem jurídico.

Em relação ao o dano imaterial ou extrapatrimonial, este não está ligado ao patrimônio da vítima, mas refere-se a todos os direitos de personalidade inerentes ao indivíduo e presentes na Carta Magna, em seu art. $5^{\circ}, \mathrm{V}$ e X, como a honra, a imagem, a liberdade. Conforme dito anteriormente, trata-se de um dano cujo conteúdo não é pecuniário, pois não está relacionado ao patrimônio da vítima, mas à forma como ela é vista na sociedade e o que as pessoas pensam sobre ela (GAGLIANO, 2011, p.86)

\subsection{O dano existencial}

O dano existencial, por sua característica notadamente subjetiva, gera dificuldade tanto na quantificação quanto na qualificação. Essa dificuldade não se dá em relação ao bem jurídico a ser tutelado, mas à impossibilidade de se efetuar uma avaliação objetiva do dano. $\mathrm{O}$ dano existencial está inserido na categoria dos danos extrapatrimoniais, ou seja, aqueles que superam a esfera do Ter, atingindo a esfera do Ser. Dessa forma, o dano existencial, considerado em uma análise mais subjetiva, necessita de interlocução com outras áreas do saber para que seja compreendido em toda a sua magnitude. 
O dano moral não deve ser confundido com o existencial, já que o dano moral tange aos direitos de personalidade, trazendo lesão à esfera subjetiva, limitado a um aspecto físico e moral. A pretensão indenizatória relativa ao dano existencial tem como objetivo reparar a lesão ou mesmo uma expectativa de algo, indo além dos limites do dano moral. O entendimento na doutrina e jurisprudência pátria é de que o dano existencial seria um dano distinto, qual caberia inclusive cumulação ao dano moral.

Os direitos à honra, ao nome, à intimidade, à privacidade, e à liberdade estão englobados no direito à dignidade, verdadeiro fundamento e essência de cada preceito constitucional relativo aos direitos da pessoa humana. $\mathrm{O}$ dano existencial se configura pela lesão a direitos existenciais e por isso fere a dignidade da pessoa humana, resultando em um vazio existencial.

Esse vazio caracterizado pelo dano existencial estará materializado por meio da lesão a um projeto de vida que compromete a liberdade de escolha da vítima, sua individualidade, ou por meio da lesão à vida em relações que impedem seu desenvolvimento social. Em ambos a dignidade da vítima será ferida, deixando a vítima do dano em situação de inferioridade e com prejuízo à sua felicidade e bem-estar.

O dano existencial pode ser caracterizado como a lesão ao complexo de relações que auxiliam no desenvolvimento normal da personalidade do sujeito, abrangendo tanto a ordem pessoal, como a ordem social. Seria uma afetação negativa de atividade que a vítima realizava em seu cotidiano e que, em razão do efeito lesivo, precisou modificar ou mesmo suprimir de sua rotina. (SOARES, 2009)

Há uma tendência de constitucionalização do Direito Civil, com preeminência das situações existenciais sobre as patrimoniais. É latente a necessidade de sistematização e distinção dessas situações, e a superioridade normativa da constituição aponta para uma valorização da dignidade da pessoa humana e os direitos de personalidade. A base axiológico-normativa do dano extrapatrimonial está na dignidade da pessoa humana. (KONDER, 2015)

\section{Nos dizeres de Maria Celina Bodin de Moraes (2003):}

[...] Aqui, e desde logo, toma-se posição acerca da questão da tipicidade ou atipicidade dos direitos da personalidade. Não há mais, de fato, que se discutir sobre uma enumeração taxativa ou exemplificativa dos direitos da personalidade, porque se está em presença, a partir do princípio constitucional da dignidade, de uma cláusula geral de tutela da pessoa humana. Como regra geral daí decorrente, pode-se dizer que, em todas as relações privadas nas quais venha a ocorrer um conflito entre uma situação jurídica subjetiva existencial e uma situação patrimonial, a primeira deverá prevalecer, obedecidos, assim, os princípios constitucionais que estabelecem a dignidade da pessoa humana como o valor cardeal do sistema.

Via de regra, a doutrina aborda o dano existencial na perspectiva das relações trabalhistas, em geral associado à fragilidade do trabalhador diante do empregador, ou a situações de assédio moral, as quais ferem a dignidade do indivíduo sobremaneira.

De fato, há uma aproximação no objeto a ser estudado, no entanto, a disciplina Direito do Consumidor traz uma abordagem calcada na liberdade artificial de escolha, na perda da individualidade e capacidade de discernimento, além de aspectos emocionais relacionados à aceitação no meio social, que prescindem de análise mais profunda.

A esse respeito, o sociólogo Zygmund Bauman (2000) traz importantes reflexões, quando preleciona que a individualidade está relacionada com o imperativo de consumo, pela primazia do querer, no imediatismo, gerando perda de identidade. Em virtude dessas questões serem trazidas à tona recentemente no ordenamento jurídico pátrio, há dificuldade de adequa- 
ção dos mecanismos jurídicos de análise e resolução desse tipo de litígio. De fato, resta discutir qual seria o parâmetro objetivo que daria ao direito as condições necessárias para normatizar esse dano.

Ainda de acordo com os ensinamentos e Maria Celina Bodin de Moraes (2003), serão considerados os aspectos componentes dos substratos ou postulados materiais do princípio da dignidade da pessoa humana. Os quatro principais corolários desse princípio são igualdade, liberdade, integridade psicofísica e solidariedade. A integridade psíquica pode ser entendida como violação à saúde, ao bem-estar físico. O dano que compromete a integridade psíquica pode ser atestado pelo médico, mas também pela prova testemunhal.

A igualdade visa para restabelecer o equilíbrio nas relações sociais, prelecionando que as diferenças não inferiorizem os desiguais, mas que seja considerada quando eventualmente se pense em discriminação. A liberdade é mais associada ao campo do Direito Penal. Na esfera civil, liberdade é autodeterminação, a capacidade de fazer escolhas, com limites e exercida dentro de determinados patamares.

No âmbito da integridade psicofísica há genericamente a saúde e o bem-estar. A solidariedade é a idéia de pertencimento a determinado grupo, considerada como um princípio esquecido, e nesse contexto há que se reafirmar a importância da participação cívica no enfrentamento às violações presentes nas relações de consumo.

A jurisprudência brasileira em relação ao dano existencial na relação de consumo ainda é tímida, mas, ainda assim, é possível encontrar julgados bem fundamentados:

EMENTA: Caso conhecido como das "pílulas de farinha", sendo de se anotar que o fato de o STJ admitir a indenização em ação civil pública promovida pelos danos decorrentes da ingestão do anticoncepcional Microvlar, da Schering [Resp. 866.636 $\mathrm{SP}$ ], referendando-a em ação individual [Resp. 1.096.325 SP], constrói modalidade de sentença de efeito erga omnes quanto ao tema jurídico, desautorizando decisões diversas quando as situações fáticas se assemelham - Hipótese em que a autora, com a juntada de carteia e duas drágeas restantes que não possuíam os princípios ativos a que se destinavam, prova ter engravidado pela falha da indústria em não destruir os produtos manufaturados para testes [placebos] da máquina empacotadora recém adquirida e pela culpa quanto à guarda desse material que, infelizmente, foi inserido no comércio como produto regular - Dever de compensar a mulher pela concepção indesejada ou inesperada, como espécie de dano existencial, conforme já admitido pelo Tribunal Superior, inclusive em lide ajuizada por defeito de outro anticoncepcional produzido pela Schering [Resp. 918.257 SP] e de pagar pensão à filha, aceita essa fórmula de indenizar como reparação pela perda de chance de cumprir o princípio do cuidado previsto na Constituição Federal, no Estatuto da Criança e do Adolescente e na Convenção Internacional sobre os Direito da Criança. Agravo retido não provido e provimento em parte dos recursos [apenas para consignar que a correção monetária do dano moral tem início a partir da sentença que arbitrou o quantum e para elevar a verba honorária para $10 \%$ do valor atualizado das condenações .(TJ-SP - APL: 4820374000 SP, Relator: Enio Zuliani, Data de Julgamento: 29/01/2009, 4 a Câmara de Direito Privado, Data de Publicação: 04/02/2009)

EMENTA: SUMÁRIO. APELAÇÃO CÍVEL. DEMORA NA ENTREGA. FALHA NO SERVIÇO. DANO MORAL IN RE IPSA. O fornecedor de serviço não cumprindo o disposto no artigo $14, \S 3^{\circ}$, do CDC e do artigo 333 , II, do CPC, torna verossímil as alegações do consumidor, ensejando a aplicação do artigo 14, caput, do CDC no julgamento da presente lide e o dever de indenizar o dano moral in re ipsa. No caso sub judice, se aplica a Teoria do dano existencial, qual seja, a espécie de dano extrapatrimonial ou imaterial, que pode ser identificado como a perda da qualidade de vida do indivíduo, ora consumidor, que, a partir da lesão sofrida, altera ou até mesmo perde a possibilidade de manter as suas atividades cotidianas. Desprovimento ao recurso. (TJ-RJ - APL: 00194167620108190202 RJ 001941676.2010.8.19.0202, Relator: DES. ANDREA FORTUNA TEIXEIRA, Data de Jul- 
gamento: 30/06/2015, VIGÉSIMA QUARTA CAMARA CIVEL/ CONSUMIDOR, Data de Publicação: 02/07/2015 00:00).

Nesse sentido, é preciso um maior esforço argumentativo no âmbito dos Tribunais para se infirmar o reconhecimento do dano existencial do consumidor como uma espécie autônoma de dano e que seja reconhecida de forma ampla e integral, nos exatos termos do artigo $6^{\circ}$, VI da Lei 8.078/90 (CDC).

\subsection{Vulnerabilidade existencial}

Antes do CDC (Lei no 8.078/90) acreditava-se, quando da formação de contratos, que ninguém celebraria contratos que não fossem vantajosos, ou que tivessem uma relação ganhaganha. No entanto, o código vem com um elemento garantidor da igualdade, visando equalizar ou equilibrar minimamente as relações de consumo. Esse elemento é o reconhecimento da vulnerabilidade do consumidor, o qual não visa outorgar vantagens ao mesmo, mas um equilíbrio contratual, como um instrumento para a harmonização das relações de consumo, buscando a satisfação coletiva e o bem-estar social.

A concepção de vulnerabilidade do consumidor em relação ao fornecedor de produtos e serviços, bem como às pressões midiáticas, é assunto reconhecido no Código de Defesa do Consumidor. No entanto, o aprofundamento no estudo do tema suscita novos vieses de análise dessa condição sumariamente explicitada no presente ensaio. A vulnerabilidade existencial encontra escopo na insuficiência do paradigma voluntarista da vontade formal.

Esse paradigma diz respeito à concepção que permeava o Direito Civil clássico: o princípio fundamental por trás da validade e eficácia vinculante os contratos era a liberdade de contratar. Ao contratar, o contratante estaria adstrito ao contrato. O fato é que, os contratantes, impulsionados por suas necessidades viam-se sem escolha e impelidos a celebrar contratos desvantajosos. (KONDER, 2015)

Ao longo do século XX, o Direito privado foi paulatinamente se afastando dessas concepções limitadas para se reconstruir em consonância com novos valores calcados na idéia de autonomia privada, extrapolando a liberdade negativa e formal. Outrossim, não mais se limitou o Direito Privado à igualdade formal, atribuindo caráter normativo à igualdade substancial.

A perspectiva de racionalidade limitada do agente econômico elucida uma melhor compreensão da idéia de vulnerabilidade. Essa racionalidade limitada será também objeto de importantes estudos na seara da Escola da Economia Comportamental, tratada no capítulo seguinte. Estes estudos atingem inclusive a questão do superendividamento do consumidor, com base em critérios comportamentais na tomada de decisões.

A vulnerabilidade, ponto fulcral na lei que disciplina a tutela ao consumidor brasileiro, tem como base a idéia de justiça e igualdade. Esse princípio visa ampliar o equilíbrio na relação, ao dispor das atribuições e funções das partes envolvidas no processo de consumo. (OLIVEIRA e CARVALHO, 2016)

A concepção de vulnerabilidade existencial relaciona-se com a suscetibilidade do indivíduo a ser atingido em sua esfera extrapatrimonial. Difere da vulnerabilidade patrimonial por esta estar relacionada à inferioridade contratual, com efeitos indiretos à personalidade do indivíduo. Diante da vulnerabilidade patrimonial, a atuação do Poder Judiciário consiste em recursos aos instrumentos jurídicos relativos às relações patrimoniais. (KONDER, 2015) 
A respeito da vulnerabilidade existencial, há demasiada dificuldade por parte do Estado em reconhecer a necessidade eminente desse âmbito de tutela ao consumidor, e isso ocorre devido à não adequação das técnicas utilizadas em outras situações para esses valores. $\mathrm{O}$ ideal seria a criação e mecanismos adequados para esse fim, e já existe de forma experimental, com base em novos estudos acerca do tema. (KONDER, 2015)

Diversos grupos podem ser considerados quando se fala em vulnerabilidade existencial. Dentre eles, os idosos, as crianças, pacientes médicos, entre outros. No entanto, essa qualificação em categorias não é o mais importante, e sim o reconhecimento da vulnerabilidade e sua relação com a dignidade da pessoa humana e solidariedade social. Não obstante, a criação e sistematização e instrumentos jurídicos adequados às situações existenciais são imprescindíveis para a superação desses paradigmas de tutela.

\section{A ANÁliSE ECONÔMICA dO DIREITO, ASSÉdIO DE CONSUMO E SUPERENDIVIDAMENTO}

A ciência do Direito possui capôs de atuação atrelados a diversas áreas do conhecimento, dentre eles a filosofia, a história, a sociologia, a antropologia e, mais recentemente, estudos relacionados à economia têm surgido e ganhado notoriedade no âmbito acadêmico. O Direito do Consumidor preza pela proteção a bens jurídicos como a vida e a saúde do destinatário final dos produtos e serviços fornecidos no mercado, considerando a condição de vulnerabilidade do consumidor mediante o fornecedor de produtos e serviços. (OLIVEIRA e FERREIRA, 2012)

Há uma concepção que trata da racionalidade econômica relacionada à conduta do fornecedor, muito presente na escola da Economia Comportamental e nos preceitos oriundos da disciplina Direito do Consumidor. Essa concepção sugere que os indivíduos reagem a incentivos e procurarão, diante da tomada de decisões, optar pela solução que o favoreça, ponderando a relação custo-benefício. Nesse sentido, as sanções teriam como fundamento desestimular condutas ou práticas nocivas. (OLIVEIRA, 2017)

Estudos recentes acerca da chamada "teoria da decisão racional" culminaram em importantes conclusões para a compreensão adequada do processo de tomada de decisão humana. Esses estudos, que compõem a denominada Escola da Economia Comportamental (Behavioral Economics), têm demonstrado que, se a decisão humana é racional, trata-se, em verdade, de uma racionalidade limitada, capaz de conduzir suas escolhas de forma sistemática e previsível para opções em confronto com seus interesses. (OLIVEIRA, 2017)

As iniciativas do mercado visam aproveitar "a irracionalidade e inconsistência das preferências dos agentes econômicos a favor destes". Em relação à vulnerabilidade do consumidor, princípio aceito universalmente nesta matéria, as conclusões obtidas pela Escola da Economia Comportamental corroboram, também no plano das ciências afins, o princípio legal da vulnerabilidade do consumidor. (OLIVEIRA e SARAIVA, 2016)

No Brasil, com exceção da última década, o país sempre fora mal visto pelo capital estrangeiro, pois comprometeu sua capacidade de atrair investimentos em razão de políticas econômicas malsucedidas, que geravam o superendividamento público, sem a correspondente geração de renda para a maior parcela de sua população. Isso tudo gerava incerteza para os investidores internacionais.

Com o fortalecimento de sua economia, através da estabilização da moeda, da superação do colapso inflacionário, da acumulação de divisas internacionais, do superávit em sua balança comercial, da geração de empregos e do cumprimento irrestrito às exigências e das obrigações 
perante o Fundo Monetário Internacional, da valorização no mercado externo de suas comodities, o Brasil despontou como um país emergente e o contínuo crescimento de seu Produto Interno Bruto-PIB atraiu investimentos internacionais, sem que isso signifique, necessariamente, melhor distribuição de renda, ou maior capacidade deliberativa do país na Comunidade Internacional.

O amadurecimento de suas bases econômicas atraiu interesses de grandes grupos multinacionais, cujas empresas precisavam de parâmetros claros para aferir a viabilidade de seu investimento, ou seja, passaram a eleger determinados critérios bastante curiosos, senão vejamos aquele que avalia a judicialização dos riscos ao capital.

É avaliada a (in)capacidade do Estado brasileiro (leia-se legislativo, executivo e judiciário) de promover normas capazes de proteger o cidadão da voracidade especulativa do mercado, o que, nas relações de consumo, é um dado extremamente importante. Em apertada síntese, quanto mais ineficazes as normas de um Estado em relação ao seu cidadão- consumidor, mais leniente o Executivo em apresentar políticas públicas de reconhecimento da inferioridade econômica, e mais lento e conservador o Judiciário para responder a esses conflitos, menor o risco de prejuízo econômico, maior o grau de investimento no país, por mais paradoxal que essa conclusão possa transparecer.

As grandes multinacionais de hoje, muitas vezes, têm mais poder político do que os próprios Estados Nacionais. Muitas diretrizes da economia mundial não são apresentadas por um consenso internacional entre os Estados, mas por uma necessidade, por uma contingência econômica voltada para atender aos interesses de determinados grupos econômicos detentores do capital de investimento. Ao segmento empresarial sempre aproveitou um modelo de Estado Liberal e pusilânime do que dizia respeito à necessidade de impor regras claras de controle do mercado. Não há dúvida que o mercado é um dos principais focos de resistência para a emancipação solidária.

Infelizmente, não são raras as vezes em que um magistrado deixa de aplicar uma norma mais favorável ao consumidor pelo receio de desatender às expectativas econômicas de uma grande empresa multinacional, lançando mão de razões utilitaristas para justificar o injustificável, ou seja, para legitimar uma decisão que deixa de aplicar uma sanção jurídica exemplar a uma empresa pelo receio de que possa gerar consequências econômicas e sociais negativas, como a demissão de trabalhadores e perda na arrecadação tributária do ente estatal, transferindo a insegurança jurídica toda para o consumidor.

O CDC, nesse particular, promoverá a mudança de parâmetros éticos de atuação para os agentes econômicos, desde que incorporado pelo consumidor o novo modelo de educação cívica, uma vez que o cidadão só terá condições de intervir de maneira qualificada nesse debate se tiver educação para compreender os diferentes graus de comprometimento empresarial para com os deveres impostos pela lei, nivelando suas escolhas a partir de parâmetros rigorosos que considerem, por exemplo, a maior projeção de durabilidade de bens de consumo, credibilidade institucional da marca para com o atendimento às demandas dos consumidores e etc.

O empresário que não se antecipa às predileções do consumidor, ou aquele que não reconhece ou valoriza a opinião do consumidor, estará fadado ao insucesso. A educação, nesse sentido, envolve uma obrigação recíproca entre consumidor e agentes econômicos.

O acesso à informação, por sua vez, é ponto de partida para o próprio exercício da liberdade de escolha, define os conceitos de vício e defeito na responsabilidade civil, além de ser revelar aspecto determinante para caracterização da oferta e publicidade ilícitas. 
Ademais, observa-se que a Política Nacional das Relações de Consumo por vezes é confrontada com novos desafios e necessidades dos consumidores, obrigando uma permanente atualização do microssistema normativo de proteção ao consumidor, de modo a oxigenar os métodos de solução de conflitos.

Uma delas é a temática do "Superendividamento", que decorre da incapacidade do consumidor de fazer escolhas racionais no mercado, em razão da influência negativa da publicidade de massa e do assédio de consumo, sendo atingidos pelo padrão estético de uma indústria cultural implacável, o que o leva a contrair dívidas não condizentes com seu orçamento doméstico ou mesmo com a realidade econômica do país.

A concessão de crédito irresponsável precisa ser melhor normatizada, sobretudo quando ocorre em detrimento dos idosos, hoje considerados em sua vulnerabilidade agravada (hipervulnerabilidade).

Os apelos de consumo padronizados e que simulam um modelo de vida ideal e fantasiado merecem uma melhor regulação, ou seja, o consumidor precisa de melhores instrumentos para se contrapor às ofertas da indústria cultural.

A indústria cultural dita modelos de comportamento pré-estabelecidos, define quais serão as novas necessidades de consumo em escala global, interfere no senso estético, informa aquilo que deverá ser adquirido para se alcançar um pseudo status social e até mesmo para a realização pessoal. O consumidor está sendo doutrinado a ter seus hábitos de consumo decididos por terceiros, uma espécie de servidão voluntária, em que se revela mais cômodo aceitar os padrões impostos pela indústria cultural, a ter que fazer escolhas por si próprio. A abordagem utilizada é agressiva, fruto de um verdadeiro assédio, subjugando a capacidade de escolha e reflexão do consumidor, obrigando-o a decidir por impulso e de acordo com um único padrão estético estabelecido.

A sociedade de consumo acostumou-se com o obsoletismo planejado, pois a ideia de durabilidade de bens de consumo não agrada ao mercado, que sempre almejou a circulação contínua de bens de consumo e, nos últimos anos, também se incorporou aos hábitos do consumidor global, na medida em que sua insatisfação pessoal com a vida ou mesmo suas carências emocionais e sociais podem ser facilmente compensadas pela satisfação e prazer de comprar. A ideia aqui não é satisfazer uma necessidade real de consumo, normalmente associada à utilidade daquele bem para uma finalidade específica, mas sim uma necessidade aparente, às vezes relacionada a autoafirmação do sujeito, concebida pela criatividade publicitária, que cumprirá uma finalidade ilusória e, naturalmente, passageira.

Em linhas gerais, vive-se numa espécie de "economia do endividamento", onde o consumidor se mostra excessivamente dependente do crédito, contraído de modo irracional e compulsivo. $\mathrm{O}$ endividamento acaba funcionando como meio de financiar a atividade econômica e como forma de suprir as necessidades básicas das famílias brasileiras.

O ideal seria, promover uma "economia de poupança", que tem a lógica inversa e pressupõe políticas públicas que promovam a educação financeira, o acesso qualificado à informação pré-contratual e o combate efeito ao assédio de consumo e aos métodos comerciais coercitivos.

Esse cenário faz o consumidor imergir num permanente estado de dano existencial, seja porque sua felicidade, artificialmente concebida pela indústria cultural, será dependente dos símbolos de consumo, propositalmente substituídos com a mesma velocidade com que surgiram no mercado, seja porque sua incapacidade financeira de acompanhar os padrões de consumo lhe imporá umas jornadas de trabalho extraordinárias, privação da convivência familiar, do 
ócio e, para agravar, como as relações interpessoais não mais são autênticas, basta simular pseudo sensações de bem estar nas redes sociais, para que a falseada ideia de felicidade seja alcançada.

Todavia, o indivíduo está isolado, marginalizado pelo consumo compulsivo e sofrerá só, o que denota um sentimento de "mal-estar difuso" numa sociedade doente, daí porque a ideia de dano existencial se justifica, sendo mais que oportuna a discussão acerca de um dever geral de prevenção e o próprio elastecimento do instituto da responsabilidade civil consumerista para o reconhecimento desse novo dano transindividual e de caráter abstrato, mas que ainda não encontra a devida tutela no âmbito do Judiciário, ainda atrelado à vetusta noção de dano individual.

Portanto, as contradições acerca dos temas supracitados podem ser dirimidas mediante esse importante diálogo com as outras esferas do saber, que corroboram a necessidade de uma concepção de tutela cada vez mais engajada na via humanística e menos patrimonial no que tange aos anos sofridos pelo consumidor diante da indústria cultural e da sociedade de consumo.

\section{CONCLUSÃo}

Atualmente, diante da indústria cultural e do apelo midiático, consumidor exerce apenas uma liberdade artificial de escolha, numa espécie de servidão voluntária, que consiste na submissão espontânea aos padrões referenciais de consumo estabelecidos pelos detentores dos meios de produção. A vulnerabilidade está calcada na idéia de inferioridade econômica, no sentido de incapacidade de intervir no processo produtivo, bem como nos contratos.

O falseado padrão de qualidade de vida imposto pelo consumismo é uma utopia inalcançável, mas que tem, cada vez mais, influenciado o indivíduo a reproduzir comportamentos estereotipados, alienando-se do mundo real, negando sua subjetividade numa constante imitação do outro, tornando-se, portanto, um consumidor permanentemente frustrado, infeliz e, em alguns casos mais recentes, revoltado por não conseguir satisfazer suas mais variadas necessidades artificiais criadas pela indústria cultural.

Não há dúvida de que aspectos culturais e econômicos são os grandes condicionantes da humanidade e, na sociedade globalizada, acabaram se fundindo num modelo de consumismo irresponsável e que justificou a necessidade de uma proteção mais elástica do consumidor, destarte, no âmbito da comunidade internacional.

Nos dizeres de Cláudia Lima Marques (2013):

$$
\begin{aligned}
& \text { [...] a atual globalização-como nunca antes-modificou nosso sentimento de tempo e } \\
& \text { espaço: tudo está mais perto, tanto as nações, quanto as pessoas, tudo mais rápido e } \\
& \text { urgente, fugaz! O Direito Internacional Privado, direito dos conflitos e dos diálogos } \\
& \text { das leis no espaço, ganhou assim conjuntura e atualidade. E, parece-me, a sua ima- } \\
& \text { gem de pessoa também restou alterada. }
\end{aligned}
$$

A fascinação do consumidor globalizado com este modelo é evidente, o que convalida a sua própria vulnerabilidade e necessidade de proteção jurídica diferenciada, pois não são raras as notícias de pessoas que passam dias na fila, em condições climáticas extremas, para serem os primeiros a adquirirem os novos modelos de bens de consumo da moda, muitas vezes em preços estratosféricos e sem grandes ou sensíveis diferenças em relação aos modelos anteriores, apenas para aplacarem uma ansiedade de consumo doentia vivenciada em escala global. 
A partir do entendimento de que o consumidor se encontra em uma dimensão transnacional, é preciso focar não somente nos aspectos econômicos da relação de consumo, mas também nos seus sujeitos, cada vez mais "coisificados" pelo mercado, ou seja, é preciso humanizar o consumo no ambiente hostil de uma globalização já fragmentada por tantas vicissitudes.

A tutela ao consumidor em relação aos danos não quantificáveis exige uma análise mais profunda acerca do sentido e alcance do princípio da dignidade da pessoa humana no âmbito das relações de consumo, pois a compulsão pelo consumo leva o sujeito a um permanente estado de frustração, ansiedade, forjando aquilo que viria a ser a figura do dano existencial

Dessa forma, é imprescindível a ampliação de novos espaços de debate, baseados na participação cívica entre a coletividade de consumidores, visando apoio e solidariedade mútua e dessa forma, compreender a evolução dos paradigmas enfrentados atualmente, favorecendo soluções para a criação e aperfeiçoamento das normas de consumo.

\section{REFERÊNCIAS}

ADORNO, Theodor W. HORKHEIMER, Max. Dialética do esclarecimento: fragmentos filosóficos. Tradução de Guido Antonio de Almeida. Rio de Janeiro: Jorge Zahar, 1985.

BAUMAN, Zygmunt. Vida a crédito: conversas com Citlali Rovirosa-Madrazo /tradução Alexandre Werneck. - Rio de Janeiro: Zahar, 2010.

BRASIL. Constituição da República Federativa do Brasil. 7.ed. São Paulo: Saraiva, 2010.

Lei $n^{0}$ 8.078, de 11 de setembro de 1990. Código de Defesa do Consumidor. Brasília, DF, Disponível em: <https://www.planalto.gov.br/ccivil_03/Leis/L8078.htm>. Acesso em: 25 out. 2017.

. Tribunal de Justiça do Estado de São Paulo. Apelação Cível no 4820374000. Relator: Des. Enio Zuliani, 2009.

. Tribunal de Justiça do Rio de Janeiro. Apelação Cível nº 00194167620108190202 RJ 0019416-76.2010.8.19.0202. Relatora: Des. Andrea Fortuna Teixeira, 2015.

CHAMONE, Marcelo Azevedo. O dano na responsabilidade civil. Revista Jus Navigandi, Teresina, ano 13, n. 1805, 10 jun. 2008. Disponível em: 〈https://jus.com.br/artigos/11365>. Acesso em: 18 jan. 2017, 9h00.

GAGLIANO, Pablo Stolze. Novo curso de Direito Civil, Ed. Saraiva, 2011.

GUISÁN, Esperanza. Más allá de la democracia. Madrid: Editorial Tecnos S.A, 2000.

KONDER, Carlos Nelson. Vulnerabilidade patrimonial e vulnerabilidade existencial: ppor um sistema diferenciador. Revista de Direito do Consumidor. vol.99. ano 24. P.101-123. São Paulo: Ed. RT. Maio-junho de 2015.

MARQUES, Cláudia Lima. "A proteção dos consumidores em um mundo globalizado: Studium Generale sobre o consumidor como Homo Novus”.'Revista de Direito do Consumidor, São Paulo, ano 22, Vol. 85, jan-fev/2013

MELLO, Fernando de Paula Batista. O Dano não patrimonial transindividual. Revista de Direito do Consumidor: RDC, v. 23, n. 96. P. 41-74, nov./dez. 2014.

MORAES, Maria Celina Bodin de. Danos à Pessoa Humana. Rio de Janeiro: Renovar, 2003. 
OLIVEIRA, Amanda Flavio. Law \& Economics e Direito do Consumidor não são disciplinas incompatíveis.Revista Consultor Jurídico, 18 de janeiro de 2017, 8h00.

OLIVEIRA, Amanda Flávio de e CASTRO, Bruno Braz. Proteção do consumidor de crédito: uma abordagem a partir da economia comportamental. Revista de Direito do Consumidor, vol. 93, maio-junho 2014, p. 231-249.

OLIVEIRA, A.F. FERREIRA, F. M.S. Análise econômica do direito do consumidor em períodos de recessão. Revista de Direito do Consumidor, São Paulo, n.81, p. 13-37, jan/mar.2012

OLIVEIRA, Amanda Flávio de Oliveira e SARAIVA, Rute. O Tribunal de Justiça de São Paulo e a anulação da multa aplicada à McDonald's em razão de publicidade abusiva. Ou, a quem cabe educar nossas crianças? Revista Direito do Consumidor, n. 106, jul-agosto 2016, p. 325-356.

OLIVEIRA, Amanda Flávio de e CARVALHO, Diógenes Faria de. Vulnerabilidade comportamental do consumidor: por que é preciso proteger a pessoa superendividada. Revista Direito do Consumidor, n. 104, março-abril 2016, p. 181-202.

SOARES, Flaviana Rampazzo. Responsabilidade civil por dano existencial. Porto Alegre: Livraria do Advogado, 2009.

VERBICARO, Dennis e VERBICARO, Loiane da Ponte Souza Prado. Espaços políticos de deliberação no âmbito da política nacional das relações de consumo e seus desafios. Direito, globalização e responsabilidade nas relações de consumo. V Encontro Internacional do CONPEDI Montevidéu - Uruguai. 2016. p.79-99.

VERBICARO, Dennis. Consumer new civil-instrumental identity based on the brazilian consumer policy. In: MARQUES, Cláudia Lima, PEARSON, Gail, RAMOS, Fabiana (Editors). Consumer Protection: current challenges and perspectives. Orquestra, Porto Alegre, 2017, p. 123-139.

Recebido em: 20 ago. 2017.

Aceito em: 3 jan. 2018. 